\title{
Pengaruh Jumlah Bilah dan Sudut Pasang terhadap Daya Turbin Angin H-Darrieus Termodifikasi sebagai Pembangkit Tenaga Listrik Skala Rumah Tangga
}

\author{
Susilo $^{1)^{*}}$, Bambang Widodo ${ }^{2)}$, Eva Magdalena Silalahi ${ }^{3)}$, Atmadi Priyono ${ }^{4)}$ \\ ${ }^{1,2,3)}$ Program Studi Teknik Elektro Universitas Kristen Indonesia, Jakarta \\ ${ }^{4)}$ Program Studi Teknik Mesin, Universitas Kristen Indonesia, Jakarta \\ Naskah diterima 25 Agustus 2019; direvisi 22 September 2019; disetujui 28 Oktober 2019 \\ doi: https://doi.org/10.24843/JEM.2019.v12.i02.p08
}

\begin{abstract}
Abstrak
Bentuk sudu taper linier merupakan bentuk sudu yang paling optimal untuk kecepatan angin yang rendah. Jumlah sudu yang baik untuk kecepatan angin rendah berkisar antara 3-7 buah sudu, namun desain sudu dengan menggunakan airfoil dan profil pada sudut pasang sudu yang bagaimana memberikan daya keluaran dan tegangan keluaran yang optimal. Turbin angin didesain dengan 2 bilah dan 4 bilah dengan sudut pasang yang bisa diatur untuk mendapatkan perbedaan daya optimal masingmasing desain. Pengujian dilakukan di 3 area berbeda untuk mendapatkan gambaran geografis kondisi angin yang berbeda khususnya masalah kecepatan angin di ksiaran $2 \mathrm{~m} / \mathrm{s}-7 \mathrm{~m} / \mathrm{s}$. Pengujian dilakukan dengan luas penampang turbin angin (A) sebesar $3 \mathrm{~m}^{2}$ Hasil penelitian menunjukkan bahwa nilai terbaik diperoleh pada kecepatan angin maksimal $4 \mathrm{~m} / \mathrm{s}$ dan jumlah blade 4 sedangkan untuk nilai terkecil diperoleh pada kecepatan angin $3 \mathrm{~m} / \mathrm{s}$ dan jumlah blade 2 yaitu. Untuk nilai TSR maksimal pada kecepatan maksimal $4 \mathrm{~m} / \mathrm{s}$ terjadi pada jumlah blade 4 , sedangkan untuk nilai terendah pada kecepatan angin 3 $\mathrm{m} / \mathrm{s}$ dihasilkan pada jumlah blade 2. Melalui pengukuran berbasis teknologi smart monitoring system, dari penelitian diperoleh semakin tinggi kecepatan angin maka tegangan keluaran semakin tinggi. Semakin tinggi tegangan keluaran, semakin tinggi daya keluaran pada generator. Sudut pasang $\beta$ dan jumlah sudu mempengaruhi kecepatan putaran rotor turbin angin. Kecepatan putaran rotor turbin angin berelasi dengan tegangan keluaran generator. pada sudut pasang $\beta$ dan jumlah sudu 4 , diperoleh daya keluaran yang sebesar 150 Watt namun pada kecepatan angin $7 \mathrm{~m} / \mathrm{s}$ daya turbin yang dihasilkan mencapai 600 watt. Dengan kondisi ini cukup memenuhi untuk alternatif cadangan listrik skala rumah tangga khususnya di pedesaan dan daerah terpencil (rural area).
\end{abstract}

Kata kunci: Turbin angin, Poros horizontal. Efisiensi sistem, Tip Speed Ratio dan Daya Angin.

\section{Abstract}

The linear taper blade shape is the most optimal blade shape for low wind speeds. The number of blades that are good for low wind speeds ranges from 3-7 blades, but the blade design uses an airfoil and profile on the blade mounting angle which is how to provide optimal output power and output voltage. Wind turbines are designed with 2 blades and 4 blades with adjustable tide angles to get the difference in the optimal power of each design. Tests were carried out in 3 different areas to obtain a geographical description of different wind conditions, especially the problem of wind speed in the range of $2 \mathrm{~m} / \mathrm{s}-7 \mathrm{~m} / \mathrm{s}$. Tests carried out with a cross section area of wind turbines (A) of $3 \mathrm{~m}^{2}$ The results showed that the best value was obtained at a maximum wind speed of $4 \mathrm{~m} / \mathrm{s}$ and number 4 blade while the smallest value was obtained at wind speeds of $3 \mathrm{~m} / \mathrm{s}$ and number 2 blades namely. For the maximum TSR value at a maximum speed of $4 \mathrm{~m} / \mathrm{s}$ occurs in the number of 4 blades, while for the lowest value at $3 \mathrm{~m} / \mathrm{s}$ wind speed is produced on the number of blades 2 . From the research, the higher the wind speed, the higher the output voltage. The higher the output voltage, the higher the output power at the generator. The $\beta$ tide angle and number of blades affect the speed of the wind turbine rotor rotation. The rotational speed of the wind turbine rotor is related to the generator output voltage. at the tide angle $\beta$ and number of blades 4 , the output power of 150 watts is obtained but with wind speed $7 \mathrm{~m} / \mathrm{s}$ turbine power 600 watt achieved. With this condition, it is sufficient for alternative household electricity reserves, especially in rural and remote areas (rural areas).

Keywords: Wind turbines, Horizontal rotor, System Efficiency, Tip Speed Ratio and Wind Power.

\section{Pendahuluan}

Krisis energi merupakan salah satu masalah yang sedang dihadapi oleh Negara Indonesia saat ini, terutama berkenaan dengan menipisnya cadangan minyak bumi (energi fosil) dan semakin tingginya jumlah penduduk. Ketergantungan terhadap bahan bakar fosil sebagai penggerak mesin-mesin pembangkit listrik, setidaknya memiliki tiga ancaman serius, yakni menipisnya cadangan minyak bumi yang diketahui (bila tanpa temuan sumur minyak baru), kenaikan/ketidakstabilan harga akibat laju permintaan yang lebih besar dari produksi minyak, dan polusi gas rumah kaca seperti gas $\mathrm{CO}_{2}$ akibat pembakaran bahan bakar fosil seperti minyak, gas dan batubara. Cadangan minyak masih tersedia sebesar 3,6 milyar bbl dan cadangan minyak akan habis dalam waktu 13 tahun. Cadangan gas tersedia sebesar 100,3 TSCF (Tera Standard Cubic Feet) dan cadangan gas akan habis dalam waktu 34 tahun. Demikian juga batubara masih tersedia sebesar 7,2 miliar ton dan cadangan batubara akan habis dalam waktu 16 tahun. 
Untuk mengantisipasi keterbatasan bahan bakar fosil tersebut sebagai sumber energi primer pemerintah mengeluarkan PP (Peraturan Pemerintah Republik Indonesia Nomor 79, Tahun 2014) tentang pemberdayaan energi terbarukan (antara lain: panas bumi, angin, sinar matahari, aliran dan terjunan air, serta gerakan dan perbedaan suhu lapisan laut) sebagai prioritas pengembangan energi untuk pemanfaatan sumber daya energi nasional pada periode tahun 2014 sampai dengan tahun 2050. Hal ini mendorong pengembangan terhadap pembangkit listrik energi terbarukan untuk mengurangi ketergantungan terhadap energi fosil dan mengurangi emisi gas rumah kaca, yang salah satunya adalah energi angin. Walaupun pemanfaatan energi angin dapat dilakukan di mana saja, akan tetapi perlu identifikasi daerah-daerah yang memiliki potensi energi angin yang tinggi agar pemanfaatan energi angin ini lebih kompetitif dibandingkan dengan energi alternatif lainnya. Oleh karena itu studi pemanfaatan energi angin ini sangat perlu dilakukan guna mengidentifikasi daerah-daerah yang memiliki potensi angin.

Potensi energi angin di Indonesia umumnya berkecepatan lebih dari 5 meter per detik $(\mathrm{m} / \mathrm{s})$ [3]. Hasil pemetaan Lembaga Penerbangan dan Antariksa Nasional (LAPAN) pada 120 lokasi menunjukkan bahwa, beberapa wilayah memiliki kecepatan angin di atas $5 \mathrm{~m} / \mathrm{s}$, masing-masing Nusa Tenggara Timur, Nusa Tenggara Barat, Sulawesi Selatan, dan Pantai Selatan Jawa. Adapun kecepatan angin $4 \mathrm{~m} /$ detik hingga $5 \mathrm{~m} /$ detik dengan potensi kapasitas 10-100 kW.

Salah satu komponen utama turbin angin adalah rotor. Fungsi utama rotor adalah mengubah energi kinetik angin menjadi energi kinetik putar yang selanjutnya diubah menjadi energi listrik oleh generator arus searah (Direct Current/DC). Dengan mempertimbangkan rugi-rugi (losses) pada generator, rotor dirancang agar mampu menghasilkan daya rancangan pada kecepatan angin tertentu (on-design). Dengan menyelaraskan torsi awal rotor dan torsi awal generator, maka diperoleh kecepatan angin untuk memutar sudu pada rotor (start-up). Apabila angin start-up tersebut masih terlalu tinggi atau tidak sesuai dengan kondisi angin dimana turbin angin dipasang, maka perlu dilakukan modifikasi. Beberapa modifikasi untuk menurunkan kecepatan angin start-up adalah dengan menambah sudut pasang (pitch) sudu (Sulistyo, A. \& Ahmad, J., 2011), dan menambah jumlah sudu yang telah ditentukan berdasarkan standar internasional yang mengatur pengukuran performa daya listrik yang dihasilkan oleh turbin angin yaitu IEC 61400-12-1. 2005 (IEC, 2005).

\section{Metode Penelitian}

Prosedur penelitian ini diawali dengan mencari NACA airfoil sudu yang digunakan dalam penelitian pada software Qblade, dalam tahap ini sudu yang telah disimulasikan tersebut akan didapat desain NACA airfoil lalu sudu dibuat untuk dilanjutkan ke tahap pengujian. Tahap pengujian dalam pengambilan data dilakukan di outdoor pada lantai 3 fakultas teknik UKI, tahap pengambilan data ini dilakukan 3 tahap, yaitu jumlah sudu, sudut pitch dan kecepatan angin.

Prosedur penelitian ini akan dilaksanakan dalam beberapa tahapan penelitian yaitu :

1. Studi Awal Disain Turbin Angin.

a. Data Parameter Awal yang ditentukan:

- Turbin angin yang digunakan yaitu turbin angin vertikal tipe darrieus.

- Jumlah blade (bilah) =2 dan 4 .

- Sudut serang, $\alpha=0^{\circ}$ (tetap).

- Sudut pasang (pitch), $\beta$, bervariasi :15², $30^{\circ}, 35^{\circ}, 40^{\circ}$

- Jari-jari blade, $\mathrm{R}=1,06$ meter.

- Kecepatan angin, $\mathrm{V}_{1}=5 \mathrm{~m} / \mathrm{s}$ dan $\mathrm{V}_{2}(17,2 \%$ $\mathrm{V}_{1}$ ).

- Massa jenis udara, $\rho=1,225 \mathrm{~kg} / \mathrm{m}^{3}$ (Suhu $25^{0}$ )

- Generator yang digunakan yaitu generator dc magnet permanen berkapasitas $300 \mathrm{~W}$.

- Beban listrik yang digunakan yaitu untuk pengisian akumulator.

b. Seri NACA airfoil yang digunakan dalam studi/perhitungan awal yaitu seri NACA airfoil 0012h termodifikasi.

c. Melakukan Perhitungan awal sebagai data parameter awal yang akan digunakan untuk tahap selanjutnya.

Data hasil perhitungan awal yang dihasilkan berdasarkan parameter awal yang telah ditentukan yaitu : koefisien daya $C_{p}$, daya listrik $\mathrm{P}$ (Watt), jumlah putaran turbin $\mathrm{n}$ (rpm).

2. Modeling dan Simulasi Hasil Studi Awal Menggunakan software QBlade untuk menentukan seri NACA airfoil dan disain blade turbin angin yang digunakan.

a. Menggunakan parameter awal dan hasil perhitungan awal. Pemodelan dan simulasi juga dilakukan untuk jumlah sudu 4 dan 5 .

b. Hasil pemodelan dan simulasi ini akan menghasilkan model disain blade turbin angin dengan sudut pasang tertentu dan jumlah blade tertentu dengan daya keluaran listrik P (Watt) yang optimal.

3. Pembuatan Model Fisik Blade Turbin Angin berdasarkan hasil simulasi software Qblade dan pembuatan/pemasangan menara dan instalasi fisik turbin angin di lapangan.

- Perhitungan sipil untuk pembuatan menara (tower) turbin angin.

- Perencanaan pemasangan turbin angin dan instalasi listrik.

- Perhitungan biaya realisasi pelaksanaan pembuatan dan pemasangan menara dan instalasi listrik dan mekanik yang diperlukan. 
4. Tahapan Pengujian Fisik di alam terbuka, dengan pelaksanaan berikut ini:

- Pengujian dan pengukuran dilaksanakan pada:

- Pengukuran kecepatan angin (m/s).

- Pengukuran besaran listrik untuk memperoleh data: daya $\mathrm{P}$ (Watt), arus I (Ampere), tegangan $\mathrm{V}$ (Volt), putaran $\mathrm{n}$ (rpm).

- $\quad$ Beban listrik yang digunakan yaitu untuk pengisian akumulator.

Adapun langkah pembuatan model turbin angin serta pengujian fisik ini sebagai berikut:

1. Perancangan serta pembuatan pembangkit listrik tenaga angin sumbu horizontal tipe propeler menggunakan:

- $\quad$ variasi jumlah sudu 2 dan 4 dan dipilih jumlah sudu yang menghasilkan koefisien daya yang paling optimal berdasarkan hasil simulasi uji profil Qblade.

- variasi sudut pasang $\beta$ pada sudu turbin angin dan dipilih yang paling optimal berdasarkan hasil simulasi uji profil Qblade.

- seri NACA 0012H/Eppler 472 airfoil yang dimodifikasi pada sudu turbin angin ditentukan berdasarkan hasil simulasi uji profil Qblade.

- sudut serang sudu turbin angin dianggap konstan pada nilai yang ditentukan.

- turbin angin sumbu vertikal tipe darrieus.

- kecepatan angin yang diukur sesuai lokasi penelitian.

- generator DC 250W magnet permanen.

- Pemakaian beban listrik yang ditinjau berdasarkan periode tertentu dan digunakan untuk pengisian energi storage menggunakan 6-unit battere Lithium 18650 12Volt.

2. Software yang digunakan dalam simulasi uji profil dan desain sudu adalah Qblade.

3. Simulasi Qblade menggunakan parameter awal yang telah ditentukan guna mendapatkan rancang bangun sudu turbin angin yang terbaik.

4. Hasil simulasi Qblade dibuat model fisiknya di alam terbuka dan dilakukan pengujian untuk memperoleh karakteristik daya, tegangan, arus dan rpm untuk pemakaian beban listrik selama periode waktu tertentu

5. Lokasi penelitian dilakukan di Fakultas Teknik Universitas Kristen Indonesia.

Penelitian ini sangat dipengaruhi oleh kecepatan angin yang rendah dan tidak stabil yang berdampak pada daya keluaran dan tegangan keluaran generator yang tidak optimal.

\subsection{Daya Turbin Angin}

Daya adalah energi per satuan waktu. Daya angin berbanding lurus dengan kerapatan udara, dan kubik kecepatan angin, seperti diungkapkan dengan persamaan berikut : (Firman A, 2013; I Made S, 2014) :

$$
P_{W}=\frac{1}{2} \rho A v^{3}
$$

dimana:

$$
\begin{aligned}
& \mathrm{P}_{\mathrm{W}}=\text { Daya angin (watt) } \\
& \quad \rho=\text { massa jenis angin }\left(\mathrm{kg} / \mathrm{m}^{3}\right)
\end{aligned}
$$

$A=$ Luas penampang melintang aliran $\left(\mathrm{m}^{2}\right)$

$\mathrm{v}=$ kecepatan angin $(\mathrm{m} / \mathrm{s})$

\subsection{Teori Momentum Elementer Betz}

Menurut Betz, seorang insinyur Jerman, besarnya energi maksimum yang dapat diserap dari angin adalah hanya 0.59259 dari energi yang tersedia. Teori momentum elementer Betz sederhana berdasarkan pemodelan aliran dua dimensi angin yang mengenai rotor menjelaskan prinsip konversi energi angin pada turbin angin. Kecepatan aliran udara berkurang dan garis aliran membelok ketika melalui rotor dipandang pada satu bidang. Berkurangnya kecepatan aliran udara disebabkan sebagian energi kinetik angin diserap oleh rotor turbin angin. (Firman A, 2013).

Pada kenyataannya, putaran rotor menghasilkan perubahan kecepatan angin pada arah tangensial yang akibatnya mengurangi jumlah total diambil dari angin. Walaupun teori elementer Betz telah mengalami penyederhanaan, namun teori ini cukup baik untuk menjelaskan bagaimana energi angin dapat dikonversikan menjadi bentuk lainnya.

Model aliran momentum yang disederhanakan oleh Betz yaitu V1 sebagai kecepatan angin mula dengan luas kecepatan awal sebesar A1 menabrak rotor dengan luas penampang sebesar A dan memiliki kecepatan tangensial sebesar V' dan kecepatan angin yang telah tereduksi oleh penampang rotor menjadi V2 dengan luas aliran sebesar A2. Dapat dilihat pada gambar 2.1:

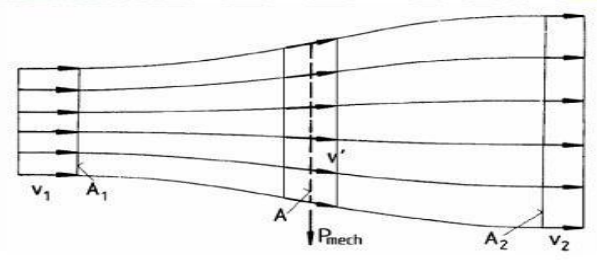

Gambar 2.1 Model aliran dari teori momentum Betz

(Firman A,2014)

Koefisien daya hasil dari konversi daya angin ke daya mekanis turbin tergantung pada perbandingan dari kecepatan angin sebelum dan sesudah dikonversikan. Jika keterkaitan ini diplot ke dalam grafik, secara langsung solusi analitis juga dapat ditemukan dengan mudah.

Dapat dilihat pada gambar 2.2 bahwa koefisien daya $\mathbf{C}_{\mathrm{p}}$ mencapai maksimum pada rasio kecepatan V2/V1 angin tertentu. 


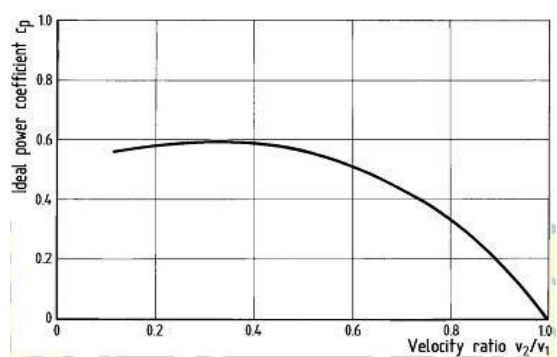

Gambar 2.2 Koefisien daya berbanding dengan rasio kecepatan aliran dan setelah konversi energi (Firman A, 2013)

Besarnya efisiensi teoritis atau maksimum dari turbin angin $\mathrm{C}_{p}$ adalah :

$$
C p=\frac{16}{7.7}=0.593
$$

Dengan kata lain, turbin angin dapat mengkonversikan tidak lebih dari $60 \%$ tenaga total angin menjadi tenaga berguna. Betz adalah orang pertama yang menemukan nilai ini, untuk itu nilai ini disebut juga dengan Betz factor.

Daya yang diekstraksi dari angin oleh rotor menggunakan kecepatan angin rata-rata ditentukan oleh :

$$
P=\frac{1}{2} m\left(v_{1}^{2}-v_{2}^{2}\right)
$$

Substitusi persamaan (2.7) ke dalam persamaan (2.8), diperoleh :

$$
\begin{gathered}
P=\frac{1}{4} \rho A\left(v_{1}^{2}-\right. \\
\left.v_{2}^{2}\right)\left(v_{1}+v_{2}\right)
\end{gathered}
$$

\section{A. Efisiensi Turbin Angin}

Daya angin maksimum yang dapat diekstrak oleh turbin angin dengan luas sapuan rotor A adalah : (Firman A, 2013; I Made S, 2014)

$$
P_{W}=\frac{16}{27} \frac{1}{2} \rho A v^{3}
$$

Pada kenyataanya karena ada rugi-rugi gesekan dan kerugian di ujung sudu, efisiensi aerodinamik dari rotor, $\eta$ rotor ini akan lebih kecil lagi yaitu berkisar pada harga maksimum 0.45 saja untuk sudu yang dirancang dengan sangat baik. Maka efisiensi rotor turbin angin menjadi :

$$
\eta_{\text {rotor }}=\mathrm{C}_{\mathrm{p}}=\mathrm{P}_{\mathrm{T}} / \mathrm{P}_{\mathrm{W}}
$$

dimana :

$$
\begin{array}{ll}
\mathrm{P}_{\mathrm{T}} & =\text { Daya turbin (watt) } \\
\mathrm{P}_{\mathrm{W}} & =\text { Daya angin (watt) } \\
\mathrm{C}_{\mathrm{p}} & =\text { Coefficient power } \\
\text { (koefisien daya) } &
\end{array}
$$

$$
\rho=\text { massa jenis angin }\left(\mathrm{kg} / \mathrm{m}^{3}\right)
$$

$A=$ Luas penampang melintang aliran $\left(\mathrm{m}^{2}\right)$

$\mathrm{v}=$ kecepatan angin $(\mathrm{m} / \mathrm{s})$

\section{B. Sudut Pasang Sudu $\beta$ (pitch)}

Menaikan sudut pasang adalah salah satu cara meningkatkan efesiensi turbin angin. Peningkatan sudut serang atau besar sudut pasang blade terhadap nilai kecepatan putar poros yang dihasilkan berbanding lurus karena adanya peningkatan gaya lift. Sudut pasang blade yang terlalu besar juga dapat mengakibatkan stall dimana terjadi peningkatan gaya drag yang berdampak menurunnya kecepatan putar poros.

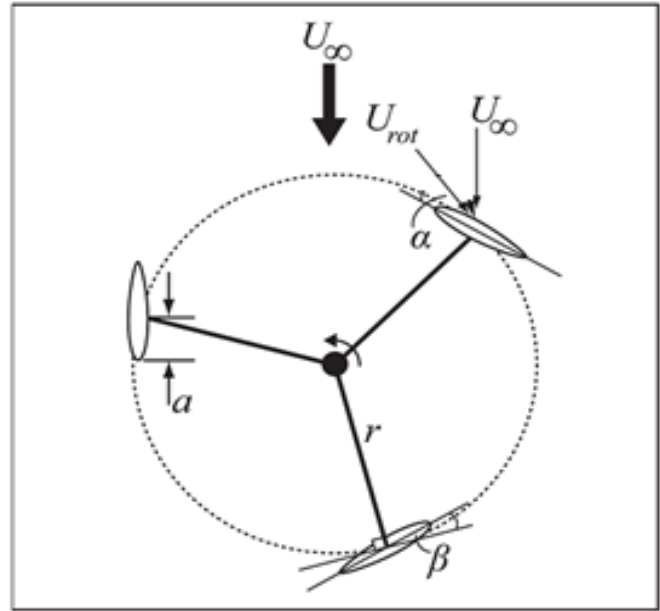

Gambar 2.3 Sudut pitch dan sudut serang pada turbin angin

Keterangan gambar:

$$
\begin{aligned}
& \beta=\text { sudut "pitch" } \\
& \alpha=\text { Sudut Serang } \\
& \bigcup_{\infty}=\text { Kecepatan angin (m/s) } \\
& \bigcup_{\text {rot }}=\text { Kecepatan putaran (rpm) } \\
& a \quad=\text { Titik lokasi Blade }
\end{aligned}
$$

Besarnya sudut pasang sudu $\beta$ (pitch) dihitung menggunakan persamaan :

$$
\beta=\arctan \left(\frac{2 R}{3 R \times T S R}\right)-a
$$

dimana :

$$
\begin{aligned}
\beta & =\text { sudut pasang sudu } \\
\alpha & =\text { sudut serang sudu } \\
\mathrm{R} & =\text { jari-jari rotor (meter) }
\end{aligned}
$$

\section{Tip Speed Ratio (TSR)}

Tip speed ratio (rasio kecepatan ujung sudu) adalah rasio kecepatan ujung rotor terhadap kecepatan angin bebas. Untuk kecepatan angin nominal yang tertentu, tip speed ratio akan berpengaruh pada kecepatan rotor. Turbin angin tipe lift (sumbu horizontal) akan memiliki tip speed ratio yang lebih besar 
dibandingkan dengan turbin angin drag (sumbu vertikal).

Tip speed ratio (TSR) dihitung dengan persamaan :

$$
T S R=\lambda=\frac{2 \pi \times r \times n}{6 n \times V}=\frac{\pi \times D \times}{6 n \times r}
$$

‘dimana :

$$
\begin{aligned}
\lambda & =\text { Tip Speed Ratio }(\text { TSR }) \\
r & =\text { jari-jari rotor (meter) } \\
D & =\text { diameter rotor (meter) } \\
n & =\text { putaran rotor }(\mathrm{rpm}) \\
\mathrm{V} & =\operatorname{kecepatan} \text { angin }(\mathrm{m} / \mathrm{s})
\end{aligned}
$$

Grafik berikut menunjukkan variasi nilai tip speed ratio dan koefisien daya untuk berbagai macam turbin angin. Pada grafik koefisien daya $\mathrm{C}_{p}$ mana yang terbaik dengan nilai kecepatan pada ujung sudu TSR dapat dilihat pada gambar 2.4.

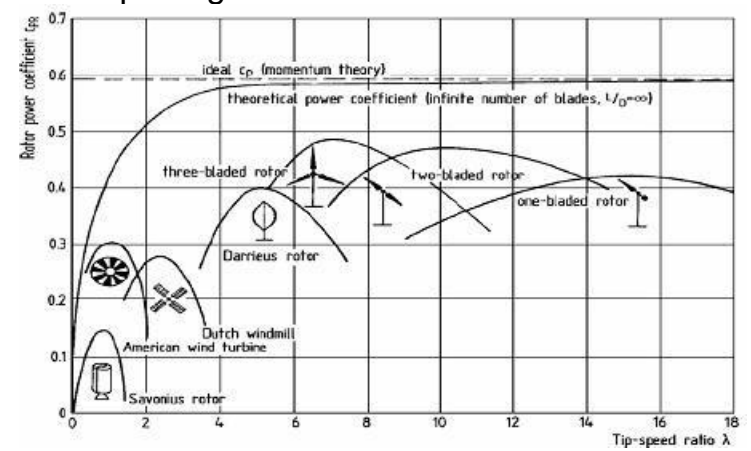

Gambar 2.4 Variasi Tip Speed Ratio dan koefisien daya pada berbagai jenis turbin angin. (Firman A, 2013)

\section{Hasil dan Pembahasan}

\subsection{Spesifikasi Bilah}

Melalui studi awal dari NACA 0012h, penelitian melakukan re-design bilah NACA dengan memodifikasi points bilah tersebut, dengan spesifikasi sesuai tabel 1.1:

Tabel 1.1 Spesifikasi geometri

\begin{tabular}{ll}
\hline Deskripsi Parameter & Ukuran/Size \\
\hline Chord Length & $250 \mathrm{~mm}$ \\
\hline Points & 121 \\
\hline Height & $1200 \mathrm{~mm}$ \\
\hline Rotor Radius & $1060 \mathrm{~mm}$
\end{tabular}

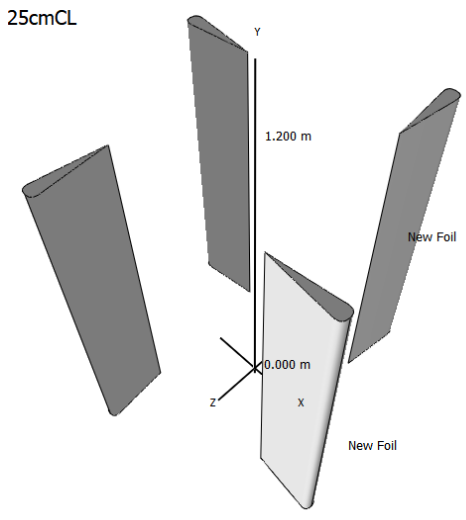

Gambar 2.5 Bilah NACA 0012h modified

\subsection{Multi Parameter VAWT Simulation}

Dengan menggunakan Software QBlade, maka Daya Angin $\left(\mathrm{P}_{\mathrm{w}}\right.$-Watt) yang mampu dihasilkan terlihat dalam tabel 1.2 dan tabel 1.3.

Tabel 1.2 Variasi windspeed, sudut pasang dengan $500 \mathrm{rpm}$

\begin{tabular}{cccccc}
\hline \multirow{2}{*}{$\begin{array}{l}\text { Wind } \\
\text { Speed }\end{array}$} & RPM & \multicolumn{4}{c}{ Pitch Angle $(\beta)$} \\
\cline { 3 - 6 } & & $15^{\circ}$ & $30^{\circ}$ & $35^{\circ}$ & $40^{\circ}$ \\
\hline $3 \mathrm{~m} / \mathrm{s}$ & 500 & 77,44 & 78,10 & 73,86 & 69 \\
\hline $4 \mathrm{~m} / \mathrm{s}$ & 500 & 77,5 & 78 & 74 & 256 \\
\hline $5 \mathrm{~m} / \mathrm{s}$ & 500 & 77,7 & 78,1 & 246,83 & 255,62 \\
\hline $7 \mathrm{~m} / \mathrm{s}$ & 500 & 77,91 & 0 & 0 & 0 \\
\hline
\end{tabular}

Tabel 1.2 menunjukkan daya angin akan dicapai optimum pada kecepatan angin $4 \mathrm{~m} / \mathrm{s}$ dengan sudut pasang $40^{\circ}$ serta kecepatan angin $5 \mathrm{~m} / \mathrm{s}$ dengan sudut pasang $30^{\circ}$ dan $40^{\circ}$.

Tabel 1.3 Variasi windspeed, sudut pasang dengan $250 \mathrm{rpm}$

\begin{tabular}{cccccc}
\hline \multirow{2}{*}{$\begin{array}{l}\text { Wind } \\
\text { Speed }\end{array}$} & RPM & \multicolumn{5}{c}{ Pitch Angle $(\beta)$} \\
\cline { 3 - 6 } & & $15^{\circ}$ & $30^{\circ}$ & $35^{\circ}$ & $40^{\circ}$ \\
\hline $3 \mathrm{~m} / \mathrm{s}$ & 250 & 9,71 & 9,775 & 0 & 0 \\
\hline $4 \mathrm{~m} / \mathrm{s}$ & 250 & 17,49 & 0 & 0 & 0 \\
\hline $5 \mathrm{~m} / \mathrm{s}$ & 250 & 0 & 0 & 0 & 0 \\
\hline $7 \mathrm{~m} / \mathrm{s}$ & 250 & 0 & 0 & 0 & 0
\end{tabular}

Kemudian Tabel 1.3 menunjukkan daya angin akan dicapai optimum hanya pada kecepatan angin $4 \mathrm{~m} / \mathrm{s}$ dengan sudut pasang $15^{\circ}$.

\subsection{Perhitungan TSR}

Bila TSR > 1 artinya lebih banyak bagian blade yang mengalami gaya angkat (lift) dan bila TSR $<1$ artinya lebih banyak bagian blade yang mengalami gaya dorong (drag).

Pada design keseluruhan turbin, diketahui radius rotor berukuran 1,06 meter, dan kecepatan angin optimum di $5 \mathrm{~m} / \mathrm{s}$. 
3.2.1 TSR ( $n=250 \mathrm{rpm})$

TSR $=2 \times 3,14 \times 1,06 \times 250$

$\begin{aligned} & 60 \times 5 \\ = & 5,547\end{aligned}$

3.2.2 TSR ( $\mathrm{n}=500 \mathrm{rpm})$

$\mathrm{TSR}=2 \times 3,14 \times 1,06 \times 500$

$\begin{aligned} & 60 \times 5 \\ = & 11,09\end{aligned}$

\subsection{Penentuan Sudut Pasang (Pitch Angle)}

Dengan asumsi sudut serang $0^{\circ}$, maka sudut pasang ditentukan dalam rumus sebagai berikut :

$$
\beta=\arctan \left(\frac{2 R}{3 R \times T S R}\right)-a
$$

3.3.1. $(\mathrm{TSR}=5,547)$

$$
\begin{gathered}
\beta=\arctan ((2 \times 1,06) /(3 \times 1,06 \times 5,547))-\alpha \\
\beta=\arctan (2,12 / 17,64)=6,84^{0}-\alpha
\end{gathered}
$$

Mencari Sudut Serang (Angle of Attack - $\alpha$ ) : $\left(\beta=15^{\circ}\right)$,

$$
\alpha=6,84^{0}-15^{0}=-8^{0}
$$

$\left(\beta=30^{0}\right)$,

$$
\alpha=6,84^{0}-30^{0}=-23,16^{0}
$$

$$
\begin{aligned}
& \text { 3.3.1. }(\mathrm{TSR}=11,09) \\
& \qquad \begin{array}{r}
\beta=\arctan ((2 \times 1,06) /(3 \times 1,06 \times 11,09)) \\
=\arctan (2,12 / 35,27)=3,43^{0}
\end{array}
\end{aligned}
$$

Mencari Sudut Serang (Angle of Attack - $\alpha)$ : $\left(\beta=15^{0}\right)$,

$$
\alpha=3,43^{0}-15^{0}=-11,57^{0}
$$

$\left(\beta=30^{0}\right)$,

$$
\alpha=3,43^{0}-30^{0}=-26,57^{0}
$$

$\left(\beta=35^{0}\right)$,

$$
\alpha=3,43^{0}-35^{0}=-31,57^{0}
$$

$$
\begin{aligned}
&\left(\beta=40^{\circ}\right), \\
& \alpha=3,43^{0}-40^{0}=-36,57^{0}
\end{aligned}
$$

\subsection{Efisiensi Turbin Angin}

$$
\mathrm{Pw}=\frac{16}{27} \frac{1}{2} \rho A v^{3}
$$

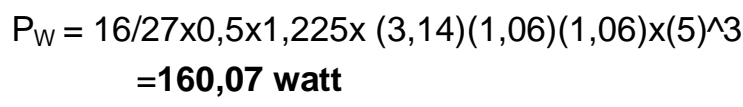

$\mathbf{P}_{\mathbf{T}}=0,5 \times 1,225 \times(3,14)(1,06)(1,06) \times(5)^{\wedge} 3$ $=270,12$ watt

3.5 Torsi Generator Listrik Turbin Angin

$$
P=(T \times N): 5252
$$

Dimana :

$\mathrm{P}$ : Daya dalam satuan HP (Horse Power)

$\mathrm{T}:$ Torsi $(\mathrm{Nm})$

$\mathrm{N}$ : jumlah putaran per menit (rpm)

5252 : nilai konstanta daya motor dalam satuan HP

$$
T=(5252 \times P): N
$$

Diketahui :

$\mathrm{P}($ generator $)=2000$ watt $=2,72 \mathrm{HP}$

Maka,

$$
\begin{aligned}
& \begin{array}{l}
\mathrm{F}=\mathrm{m} \times \mathrm{a} \\
=15 \mathrm{Kg} \times 9,8 \mathrm{~m} / \mathrm{s}=147 \mathrm{~N}
\end{array} \\
& \begin{aligned}
\mathrm{T}=\mathrm{F} \times \mathrm{I} & \text { (panjang lengan pada poros) } \\
& =147 \times 1,06=155,82 \mathrm{Nm}
\end{aligned}
\end{aligned}
$$

Hubungan Generator terhadap Torsi Rotor Turbin Angin untuk menghitung putaran rotor per menit :

$$
\begin{aligned}
N=(5252 \times P): T \\
=(5252 \times 2,72): 155,82 \\
=91,68 \mathrm{rpm}
\end{aligned}
$$

\section{Simpulan}

Dari hasil penelitian berdasarkan dimensi turbin angin yang disimulasikan dapat digambarkan bahwa dengan variasi 4 bilah dan sudut pasang (pitch) $35^{\circ}$ dan $40^{\circ}$, kecepatan angin $5 \mathrm{~m} / \mathrm{s}$ dan RPM 500 mampu menghasilkan daya turbin angin sebesar 246,83 watt sampai dengan 255,62 watt. Hal ini tentu saja, model ini menghasilkan pembangkit listrik tenaga angin skala rumah tangga yang cukup bermanfaat di daerah pedesaan dan daerah rural.

\section{Ucapan Terima Kasih}

Ucapan terima kasih kami sampaikan kepada Pihak Universitas Kristen Indonesia terkait pendanaan penelitian. Kemudian Tim Puskrenov Fakultas Teknik UKI begitu juga dengan Bapak Abner Simatupang (PKB GPIB Cinere), Bapak 
Tommy Soewarno (PKLU GPIB Cinere, Bapak Ir. Danny R. Lopulalan (PKLU GPIB Cinere), dan Bapak Ir. Robinson Purba, MT (Dosen Senior FT UKI) yang membantu penyempurnaan desain turbin angin dan penyediaan lokasi penelitian awal.

\section{Daftar Pustaka}

[1] Tushar K. Ghosh, Mark A. Prelas. 2011. "Energy Resources and Systems. Volume 2: Renewable Resources", Springer. USA.

[2] Ion Bostan, Adrian Gheorghe, Valeriu Dulgheru, Ion Sobor, Viorel Bostan, Anatolie Sochirean. 2013. "Resilient Energy Systems. Renewables: Wind, Solar, Hydro". Volume 19. Springer. USA.

[3] Siegfried Heier, Rachel Waddington. 1998. "Grid Integration of Wind Energy Conversion Systems". John Wiley \& Sons.

[4] Firman Aryanto, I Made Mara, Made Nuarsa. 2013. "Pengaruh Kecepatan Angin dan Variasi Jumlah Sudu Terhadap Unjuk Kerja Turbin Angin Poros Horizontal". Jurnal Universitas Mataram Teknik Mesin. Nusa Tenggara Barat.

[5] I Made Adi Sayoga, I Kade Wiratama, I Made Mara, Agus Dwi Catur. 2014. "Pengaruh Variasi Jumlah Sudu Terhadap Aerodinamik Performan Pada Rancangan Kincir Angin 300 watt". Jurnal Universitas Mataram Teknik Mesin. Nusa Tenggara Barat.

[6] Sulistyo Atmadi, Ahmad Jamaiudin Fitroh. 2011. "Analisa Pengaruh Sudut Pitch, Untuk Memperoleh Daya Optimal Turbin Angin LPNSKEA 50 KW Pada Beberapa Kondisi Kecepatan Angin". Jurnal Teknologi Dirgantara: Bandung.

[7] Marcel Veldy, Sapto Wiratno Satoto, Budi Baharudin. 2015. "Pengaruh Sudut Tulang Blade Terhadap Nilai Kecepatan Putar Poros Turbin Angin Horizontal Golden Blade". Jurnal Politeknik Negeri Batam Program Studi Teknik Mesin.

[8] Sulistyo Atmadi, Ahmad Jamaiudin Fitroh .2011. "Rancang Bangun Rotor Turbin Angin 10kW untuk Memperoleh Daya Optimum pada Variasi Jumlah dan Diameter Sudu". Jurnal Teknologi Dirgantara: Bandung.

[9] Farrid Ridha Muttaqin, Bambang L, Widjiantoro, dan Ali Musyafa. 2011. "Pemilihan Sudut Pitch Optimal Untuk Prototipe Turbin Angin Skala Kecil Dengan Tipe Bilah Non-Uniform Airfoil Nrel S83n". Jurnal Institut Teknologi Surabaya Teknik Industri. Surabaya.

[10]Angga Priyatna, Heri Haryanto, Ri Munarto. 2014. "Pengujian Karakteristik Generator DC Magnet Permanen Sebagai Pembangkit Listrik Tenaga Bayu (PLTB)". Jurnal Universitas Sultan Ageng Tirtayasa Teknik Elektro. Cilegon. 